\title{
The Impact of Locally Generated Television Programmes on the Kenyan Television Viewers: A Case Study of Citizen Television
}

\author{
Were J. Maende ${ }^{1}$, Makori M. Nyambane ${ }^{2}$ \\ ${ }^{1}$ University of Nairobi, School of Journalism and Mass Communication, P.O. Box 3019700100 GPO, NAIROBI \\ ${ }^{2}$ Masinde Muliro University of Science and Technology, School of Business and Economics, P.O Box 190-50100 Kakamega, Kenya
}

\begin{abstract}
This study investigated possible impact of locally generated television programmes on selected Kenyan television viewers in Dagoretti sub-location of Nairobi with particular focus on Machachari programme of Citizen Television. The objective that guided this study included: To examine the nature and the impact of information consumed by viewers among Dagoretti location residents. The study utilized the uses and gratifications and the social learning theory in examining the locally generated TV programmes. The study adopted a case study design with questionnaire and interviews being used as instruments of data collection. The researcher analyzed both primary and secondary data that provided information for the study. The study used a sample of 220 and response rate was good at $84 \%$. The findings indicated that local programmes impact positively on viewers by transferring positive messages to them like good parentage, drug abstinence and responsible youth behavior among others. With reference to the findings of this study, it is recommended that there should be an increase in locally generated programmes since majority of the viewers upheld the positive themes that they deduced from the programmes and thus parents and guardians should encourage their children to watch locally generated programmes.
\end{abstract}

Keywords: Locally generated, Nature, Impact, Viewers.

\section{Introduction}

Without a doubt, television plays a significant role in the socialization process of today's child. Most children are exposed to watching television long before they are able to read. According to the UNESCO, when a child begins to watch television at an early age, they usually begin with children programmes - revolving around puppets, animals, story-telling, and children's songs (Carlsson \& Von feilitzen, 1988). With time however, they discover adult programmes, and develop a liking for them. More importantly, they prefer the more local programmes often originating from within the society. However, when choices are available at the same time, children tend to choose the type of programme which they have previously found interesting, and thus their tastes are hardened and narrowed. This study focused majorly on the nature and impact the locally generated television content has on this group of viewers.

\section{Background of the Study}

Media has been part of the people and the world. As a significant part of most people's lives, media had undergone extreme transitions making it a progressive industry. For example in Kenya, since 1998 a remarkable change in TV Broadcasting has occurred, but it has not affected the majority of the population as television sets still remain the preserve of urban middle-class dwellers. In developed countries such as the United States and Japan, the media industry has greatly progressed as well. In most parts of the world, television is considered as the most popular and ubiquitous public medium, offering diverse and accessible entertainment that remains unmatched by print media (Abu-Lughod, 1993). Mass media, and television in particular, are forces which provide audiences with ways of seeing and interpreting the world - ways which ultimately shape their very existence and participation within society.

The liberalization of airwaves in Kenya in the 1990s by the Communication Commission of Kenya (now Communications Authority) has led to the emerging of many television stations that are competing for viewership. Consequently, the viewers are exposed to different stations ranging from free-to-air stations to Pay TV stations (such as Startimes, GoTV, DSTV) depending on viewer's choice in addition to alternative sources of information and entertainment such as the internet. This expansion of television networks has made competition for audiences increasingly fierce as television channels are seeking to consolidate the limited number of viewers available in the market. In this intense competition, it is important that television channels create a unique image of themselves that will help them stand out and be different from their competitors in order to make viewers easily identify them. This has necessitated the need for creation of a brand that is attractive and appealing to the viewers through branding.

\section{Statement of the Problem}

A number of studies have been done on the media and effects that competition has on different segment of media. For example, competitive intelligence practices by FM stations in Kenya, Sang (2001), there was a survey on advertising agencies in Kenya (Mbuthia,2003), competitive strategies adopted by KTN of the Standard Group (Karoney, 2008), competitive strategies adopted by mainstream daily print media 


\section{International Journal of Science and Research (IJSR) \\ ISSN (Online): 2319-7064 \\ Index Copernicus Value (2013): 6.14 | Impact Factor (2015): 6.391}

firms in Kenya (Mbugua, 2006) and Competitive strategies adopted by Nation Media Group Limited (Muganda, 2007). Other studies by Kandie (2001) and Kiptugen (2003) show the effects of environmental changes to firms in specific industries. However, no study has been done on impact of locally generated programmes. Yet this is a very important aspect in the broadcast industry due to the entry of many competitors. This study seeks to fill the gap in the study of television broadcast by looking at the impact of locally generated programs on Kenyan television viewers.

\section{Objective of the study}

The main objective of this study was to explore the nature and impact of locally generated television programmes Kenyan television viewers in Dagoretti Sub-Location of Dagoretti Constituency, Nairobi County.

\section{Hypotheses of the study}

The testable hypotheses for this study are:

H0: Locally generated TV programmes have insignificant impact on Kenyan television viewers.

H1: Locally generated TV programmes have significant impact of Kenyan television viewers.

\section{Significance of the Study}

This study seeks to contribute to the development of knowledge and literature on locally generated programmes. The need for local programs can be attested to the rapidly changing broadcast environment characterized by ever rising competition and uncertainties of audience behavior and attitudes. Therefore, this study will also be a significant source of information for organizations in their attempts to successfully implement local content. For Citizen TV, the findings in this study will be of help in assessing how their programmes affect viewers.

\section{Scope of the study}

The study targeted the staff and audiences of Citizen TV. Considering there are several locally generated programmes, this study focused on Machachari programme. The target population was residents of Nairobi town specifically Dagoretti location .Being Kenya's capital city, Nairobi is ideal since the proliferation of television sets is higher among its residents. The town also harbors the channels headquarters. Nairobi is also a cosmopolitan municipality and thus there will be a good representation of the sample population.

\section{Justification of the Study}

It has been observed in recent times that the local TV content in Kenya is blossoming especially in its dominance in the contents of the programming of most television stations in Kenya, especially the major towns (Nairobi, Mombasa, Kisumu, Eldoret etc (Githige, Sakwa and Kihoro, 2014). Therefore, this study seeks to draw the attention of media practitioners and owners (especially television) to the impact of locally generated TV programmes with special focus on Citizen TV. Having this fact in mind, television media practitioners and owners will be mindful of the kind of locally generated programmes they air, most especially at prime time, knowing fully the vulnerable and gullible nature of teenagers.

A research into how locally generated television programme shapes the social behaviour of public whether positively or negatively appears novel, especially in television media studies. This is a contemporary issue which scholars in the field of media studies have paid little or no attention to. Therefore, part of the uniqueness of this study is that it will be of immense significance to researchers in the academia in the 21 st Century. It does not only aim at contributing to knowledge but also providing a foundational basis for further studies into the socialization role of the locally generated television programmes.

Nonetheless, employees of Citizen TV and the public who are at the heart of this study will understand fully the impact of locally generated TV programmes in contributing to shaping their social behaviour in their immediate environment. It will also avail counselor's viable information on where and how teenagers draw inferences for their social behaviour. This is because teenagers might not only behave in a certain manner because of mere peer influence, but also from what they watch on television, especially from people or celebrities they see as role models. It is also believed that the findings of this study will be an added resource to available literature and will be used to promote informed decision-making and policies by the regulating bodies of the broadcast and entertainment industry.

\section{Literature review and theoretical framework}

\section{Emergence of local TV}

The emergence of local TV may therefore increase competition with existing broadcasters and local media for advertising revenues. Total television revenue across the country would likely be broadly the same, but the split would increase with the addition of market players at a local level. However, there remains a question over how far local TV programmes will take a share of the national revenues. This is something the Government is continuing to explore as it could prove to be a valuable revenue source for local TV. In Lim's (2008) study on the reinvention of nationalism through Malaysian Idol, she argues that the reality television format "has visibly influenced the 'identity' of both audiences and broadcast stations.

Furthermore Lim (2008) that the relationship of globalization and nationalism articulated by this format, together with the typical reality TV strategy of blurring the boundaries between entertainment and ordinary life, work together to concurrently construct a desirable 'national identity'. Her research found that audience members find a sense of national pride in Malaysian Idol despite the disjuncture of contestants performing international, non-Kenyan styles such as Rhythm and Blues. 


\section{International Journal of Science and Research (IJSR) \\ ISSN (Online): 2319-7064 \\ Index Copernicus Value (2013): 6.14 | Impact Factor (2015): 6.391}

Turning now to the broader context of reality TV scholarship, it should be noted that while numerous studies have focused on reality game shows such as Survivor (Foster, 2004; Wright, 2006) and Big Brother (Aslama, 2009; Barron, 2010), contemporary western-focused scholarship has expanded recently to take in the ever-growing proliferation of reality shows. However, there are a relatively limited number of studies on the subgenre of the reality talent contests. Furthermore, the studies on the former are predominantly dealing with European Pop Idol (Holmes, 2004), American Idol (Cowell, 2003) and Australian Idol (Roscoe, 2001) cultural contexts. Those studies that do research on reality talent contests within an Asian context have tended to concentrate on the format, from production and industrial perspectives; for example, the study of Supergirl (Keane, Fung, \& Moran, 2007; Jian \& Liu, 2009).

A study conducted by Nabi et al. (2003) among 252 residents in Tucson, Arizona found that younger people and "people with less formal education" were regular viewers of reality TV but gender and race were not significant criteria. But the study also adds that each type of reality $\mathrm{TV}$ attracts different types of audience age groups. Raphael (2009) notes that advertisers believe that reality TV, especially tabloid, crime-time and emergency programs appeal more to pre-teenagers, seniors, and low-income viewers and fail to draw the attention of wealthy 18 to 35 year-olds.

The enjoyment of watching reality $\mathrm{TV}$ also has been connected with the opportunities of socialization that it affords between viewers as they discuss the performance of a particular contestant or develop mutual preference for a certain contestant to build 'social affiliation' (Lundy et al., 2008). In other words, this capacity of reality TV to enable 'social affiliation' impacts how viewers have conversations, watch and participate in reality TV. Hill (2002) in his research on Big Brother audiences also found that "the social and performative aspects" make it popular among the audience who most enjoyed "watching the live 'eviction' show..., followed by seeing excontestants talk about their experiences ..., watching the nightly TV program ..., and talking about the program with friends/family" (Hill, 2002).

\section{Local Programmes}

The term local programme, refers to a television program produced by a television station or independent television producer for broadcast only within the station's transmission area or television market. Local programmes can encompass the whole range of programme genres but will usually only cover subjects or people of particular interest to an audience within the station's coverage area.

In Canada, for example, the Broadcasting Act provides that the broadcasting system "shall be effectively owned and controlled by Canadians, contribute to "the maintenance and enhancement of national identity and cultural sovereignty,"

\section{A Profile of Citizen Television}

Citizen TV is owned by royal media an umbrella of fourteen radio stations that cover different groups of the diverse Kenyan communities; two broadcasting in national languages while the rest are vernacular.

It was started in 1999 and re-launched in June 2006 with their slogan being the home of local programming. Since 2006 its viewership has grown to be the country's most popular in terms of audience preference commanding an unassailable $52 \%$ of television audience (Steadman Synnovate Report 2013)

In October 2014, Citizen TV was once again the clear leader in terms of both share and viewership, with an average of 1.42 million viewers per 30-minute time block. In a distant second was KTN with 535,000 viewers per time block, and third is NTV with 442,000 viewers. K24, QTV, and KBC are fourth, fifth, and sixth in terms of viewership, all with an average viewership of less than 300,000 per half-hour.

While Citizen's viewership stays much higher than it's' competition throughout the day, the channel does have daily peaks in audience size, most notably during the weeknight evening hours of $7 \mathrm{pm}-10 \mathrm{pm}$. At $7 \mathrm{pm}$ during the nightly news show Citizen Nipashe and the weekend version Nipashe Wikendi, Citizen's average viewership in October was over 2.2 million, and audience numbers stay high through the primetime schedule, never dipping below an average of 2 million viewers before 10pm ( Geopoll Research 2014)

The growth of citizen TV has largely been attributed to their strong focus on use of local actors and talent in their programs. The use of local programs is said to have resonated well with the local viewers who easily associate with the content being broadcasted. With this in mind, the study purposively picked on Machachari for the purpose of the study.

\section{Machachari programme of Citizen TV}

Machachari is a Swahili name that can translate to one being hyper, active, bold and confident. Machachari, written by Naomi Kamau, is a children comedy/ adventure series that depicts the friendship between Govi, Baha and Stella who live in the ghetto neighboring the suburban estate where their friends Almasi, Joy and Fatso live in. Theirs is a friendship that transcends society's divide of the rich and poor. The cast includes four children: Baha, Govi, Almasi and Joy. At some instances, the screenwriter foregrounds Fatso, a heavily built child who is considered the Estate's bully, or Stella, a slum lass. In this TV drama, adults are the supporting cast or secondary characters. In this respect there is Baha's and Govi's father and mother and Almasi's and Joy's mother. The latter's father seems totally absent, busy making money because he believes that providing a good life is everything for a child. Other key adult characters in Machachari include MaDVD; a youthful enterprising adult who vends cheap film DVDs and has also rented a public toilet in the slum for which he charges every visiting slum dweller. Another grown-up character is Sophia, house help to Almasi's family and girlfriend to

Volume 5 Issue 5, May 2016 www.ijsr.net 


\section{International Journal of Science and Research (IJSR) \\ ISSN (Online): 2319-7064 \\ Index Copernicus Value (2013): 6.14 | Impact Factor (2015): 6.391}

MaDVD. The last central adult is certainly Mzee Kobe; a gardener in Almasi's home.

As a children's programme, Machachari too has a plot with a beginning, middle and end. The major plot is the juxtaposition of children from two different backgrounds. Almasi and his sister Joy emanate from an affluent family. Bahati (Baha), Govi and Stella derive from lowly. The drama is heightened by the friendship of these children in spite of the polarities of their upbringing. As an episodic television drama, Machachari has no linear plot and each episode has its own major plot with the incorporation of sub-plot involving adult characters alongside the children's plot(s). In Machachari, all the major six children may be considered lead characters and indeed each episode spotlights more on one or two of the six children. In terms of plot, the screenwriter has ensured that the plots in one episode do not exceed two and are definitely not overloaded.

The setting is in a slum locality and an affluent estate. This is the true depiction of Kenya's capital town Nairobi where the poor who live in slums border the rich who reside in leafy suburb estates. The programme aptly captures its title since we see the children in the program being on toes with whatever happens around their environment. For example, they are not shy to relate with their parents, the authority and their peers. This can be seen in the program when they do take it upon themselves to report vices to their parents, and the highest authority which mainly according to the program is the area chief.

The costuming of the actors is also realistic in depicting the setting and bringing out the characters in a more Kenyan environment. In the program, the slum dwellers are costumed in what is perceived as second hand clothes while the rich are costumed in classy outfits. The story also follows the adventures of the common struggles that children undergo in their daily upbringing. In order to have a full package, the screen writer has used different stylistic devices that aid in the overall achievement of the programme. The major styles the screen writer has employed are humor, music and child centeredness.

Humour: Humor or comic relief has greatly been used in the programme to calm down tense situations, to pass a message and to kill boredom by eliciting laughter. Humour and laughter are central thoughts in children. Children themselves exhibit humour and laughter and therefore enjoy and are in fact best taught through these. Like other children, the children in Machachari bring out humor by imitating adults, and through their actions. For example, there is an episode where Baha wanted to earn some money and so he took his father's old shoes to a cobbler in exchange for some few coins. When the father returns, he starts looking for his old shoes for he had hid the house rent in the old shoes and thus Baha is forced to remember whom he gave the shoe to.

Music: Music as a style serves many purposes in drama from breaking monotony, joining of two scenes, background effects and as a medium of passing message. While music is employed sparingly in Machachari, whenever it is utilized, it not only entertains but also emphasizes the narrative development. Indeed, the song by the children that begins the programme, humorously recounts the various roles that the children play in the television drama.

Child centered: The screenplay should be about the "child world": either centered on childhood or dealing with issues from a child's angle of vision. It is doubtful that a work of art for that matter that centers on wife-inheritance, or giving birth (Alembi 2003), drugs, alcohol, death, graphic violence and sex, would be of interest to a child, unless the child is already coarse due to regrettable nurturing. In the program, the sensitive issues like physical violence, early sexual relationships, and unruly behaviour among others have been tackled from a childs perspective in the sense that though children in real life do participate in such vices, the program has given such vices less glory in order to pass a message that such vices leads to a characters downfall. The themes highlighted in the weekly episodes border on the following areas;

Responsible parentage: in the program, parents face the difficulty of raising children in these ever changing times where children are exposed to harmful worldly contents like pornography, cyber bulling, insecurity and the allure of drug abuse. In the episodes, parents are seen to be keenly paying attention to their children change of social behaviour as a way of detecting a problem in their children's lives. A major highlight of responsible parentage is the need for elders to listen to the child's voice and not to assume that they (adults) are always right.

Schooling: this is also another pronounced theme in Machachari. Children who have performed well are often rewarded with gifts and favours while those that have not performed well, are denied favours like watching television, visiting their favourite places and even being denied monetary favours. This tends to encourage children to work hard in school so as not to miss out on favours.

Children rights: this is a major theme where the plight of children in modern day society is highlighted. This ranges from corporal punishment, child abuse, child neglect, sexual abuse, right to education and identity among others.

Poverty also speaks out as an outstanding theme. The challenges slum families undergo to survive the harsh economic times is clearly seen as the social class scenario is depicted where the haves and the have not co-exist together. Despite the difference in the hierarchy of needs, the poor parents in the slums manage to raise their children by inculcating in them the need to live within their means. The rich are also seen to caution their children against spending lavishly and asking for more luxurious items that are not basic for survival.

The language used in the program is mainly Kiswahili which scores highly in the program since its Kenya's national

Volume 5 Issue 5, May 2016 


\section{International Journal of Science and Research (IJSR) \\ ISSN (Online): 2319-7064 \\ Index Copernicus Value (2013): 6.14 | Impact Factor (2015): 6.391}

language. Machachari also relies heavily on the use of sheng which is Kenya's slang language spoken mainly by urban population and mostly in the slum area. The use of all these local elements in the production of Machachari makes the target audience (children) to easily associate with the program as it mirrors their life.

In conclusion, the program is a good mirror of the present Kenyan family and their day to day struggles of bringing up the next generation. The positive themes that are communicated are also ideal to keep the balance of good versus evil in our children's lives. However the major setback of the program can be attested to the use of sheng as this greatly deteriorates the language of school going children since they will tend to model the behaviour of their favorite actors.

The program schedules on Friday 7:45pm-8:15 pm after the 7 o'clock news. This is prime time since all the family members are believed to be present in their homes. Machachari also has a repeat version that airs on Sunday 3:00pm - 3:30pm this gives opportunity to those that missed the Friday version to catch up with the program. Being a Sunday, most people are in their homes preparing for the new week and thus the program succeeds in reaching their target audience.

\section{Theoretical Framework}

In the examination of the impact of locally generated TV programmes on Kenyan viewers, this study utilizes The Uses and Gratification theory, and Social Learning theory. The study has discussed in detail in the following sections.

\section{The Uses and Gratifications theory}

What mass communication scholars today refer to as the uses and gratifications (U\&G) approach is generally recognized to be a sub tradition of media effects research (McQuail, 1994). Early in the history of communications research, an approach was developed to study the gratifications that attract and hold audiences to the kinds of media and the types of content that satisfy their social and psychological needs (Cantril, 1942). Wimmer and Dominick (1994) proposed that U\&G began in the $1940 \mathrm{~s}$ when researchers became interested in why audiences engaged in various forms of media behavior, such as listening to the radio or reading the newspaper. Still others credit the U\&G perspective with Schramm's (1949) immediate reward and delayed reward model of media gratifications (Dozier \& Rice, 1984).

Regardless, early studies were primarily descriptive, seeking to classify the responses of audience members into meaningful categories (Berelson, Lazarsfeld, \& McPhee, 1954; Katz \& Lazarsfeld, 1955; Lazarsfeld, Berelson, \& Gaudet, 1948; Merton, 1949). This latter focus of research, conducted in a social-psychological mode, and audience based, crystallized into the U\&G approach (McQuail, 1994). Some mass communication scholars cited "moral panic" and the Payne Fund Studies as the progenitor of U\&G theory. Undertaken by the U.S. Motion Picture Research Council, the Payne Fund
Studies were carried out in the late 1920s. Leading sociologists and psychologists including Herbert Blumer, Philip Hauser, and L. L. Thurstone sought to understand how movie viewing was affecting the youth of America (Lowery \& DeFleur, 1983).

The Uses and gratifications theory (Blumler and Katz Date, 1974) posits that people actively choose media Audiences choose media and the types of content that satisfy their social and psychological needs. In relation to this study, this theory best explains as to why people do change channels when watching television and settle on a program in a different television channel.

Gratification is mainly obtained from the mediums content this ranges from watching a specific program to the familiarity with the genre of the program. However, the same content in a medium may gratify people differently as different needs are associated with individual personalities, stages of maturation, social backgrounds and gender. Zillmann (cited by McQuail, 1987) has shown the influence of mood on media choice: boredom encourages the choice of exciting content and stress encourages a choice of relaxing content. With regard to this study, the theory helps us to understand why the respondents prefer watching the local programs; this might be motivated by the need to watch their favourite local characters, the educational themes being conveyed in the programs or the familiarity of the content in the programs. It is also important to note that programming is a broadcast strategy aimed to tap viewers and this theory helps in guiding the programming strategy in the sense that before a programme is created; content producers should first identify the needs of the audience and later create a program that satisfies the need. To fully satisfy the needs of the viewers, the programme should bear content that resonate with the needs of the audience.

However, there are several criticisms to this theory. First and foremost, it is hard to gauge how each audience, individual and group perceives a given media. Morley (1992) says that creators of media content have a preferred reading that they would like the audience to make out of the text. However, the audience might reject it, or negotiate some compromise interpretation between what they think and what the text is saying, or contest what the text says with some alternative interpretations. The theory also underlies the uses and gratification that audiences derive from the media rather than the outcome of the needs they seek to be gratified by the media.

\section{The Social Learning Theory}

The Social Learning Theory was propounded by Albert Bandura who was a psychologist at Stanford University. The theory suggests that much learning takes place through observing the behaviour of others (Anaeto, et al, 2008). Bandura (1986) says that "people learn behaviours, emotional reactions, and attitudes from role models whom they wish to emulate." In his earliest studies to support this theory, fondly called the "Bobo Doll Studies", pre-school children watched a film in which an adult pummeled, kicked, threw, and hammered a 3.5 feet tall, inflatable Bobo the clown doll. One- 


\section{International Journal of Science and Research (IJSR) \\ ISSN (Online): 2319-7064 \\ Index Copernicus Value (2013): 6.14 | Impact Factor (2015): 6.391}

third of the children watched the film that ended with the adult aggressor being rewarded; one-third watched a film that ended with the adult aggressor being punished and one-third saw a no-consequence version of the film. All the children were then turned loose in a playroom filled with attractive toys, including a Bobo doll. Children who saw rewarded or inconsequential aggression were more likely to beat up the Bobo doll than were children who saw punished aggression.

The results therefore, showed that whether or not the children acted aggressively depended on their observations of another person's experiences with reward and punishment, and not on their own personal experiences (American Psychological Association, n.d.). Bandura as cited in Wirtz (2009) said that "children and adults acquire attitudes, emotional responses, and new styles of conduct through filmed and televised modelling". Therefore, he placed a caution that $\mathrm{TV}$ viewing might create a violent reality, which has to be feared for its capacity to influence the way we deal with people every day. His theory can be summarized as follows: that we learn by observing others through modeling of behaviour and that vicarious behaviour are a means of modifying behavior.

In relation to the study, this theory helps in understanding the impact the local programmes have on viewers, in the sense that viewers adopted various models of action as it applies to everyday lifestyle such as clothing, appearance, style, eating and drinking, modes of interaction and personal consumption. These social effects are adopted by viewers since they are modeled by desirable actors as being fashionable, socially correct and as a way of gaining societal acceptance. This can also be attested to the fact that most organizations and companies use actors in the local programs to pass product information and for advertisements. The theory also befits this study since the televisions programs offer both audio and visual texts and thus it is easy for audiences to observe and adopt modeled behaviour. However, the major criticism of the theory is that television is rarely the only source of social learning and its influence depends on other sources such as parents, friends, teachers, etc (McQuail, 2005).

\section{Research Methodology}

The study used a case study approach. Researcher Robert K. Yin defines the case study research method as an empirical inquiry that investigates a contemporary phenomenon within its real-life context; when the boundaries between phenomenon and context are not clearly evident; and in which multiple sources of evidence are used (Yin, 1984). Case study is an ideal methodology when a holistic, in-depth investigation is needed (Feagin, Orum, \& Sjoberg, 1991). Case study research, with its applicability across many disciplines, is an appropriate methodology to use in communication studies (Robins, Dautenhahn \& Dickerson, 2009). In media and communication field, case study research has been used to study reasons why local TV programs affect particular people (McDowell \& Sutherland, 2000). As in all research, consideration in this study is given to construct validity, internal validity, external validity, and reliability. Levy (1988) established construct validity using the single-case exploratory design, and internal validity using the single-case explanatory design.

Both primary and secondary sources of data were used.

The study was carried out in Dagoretti sub-location, in Dagoretti Constituency, Nairobi County with specific target being Citizen TV's audiences and staff. The choice of Dagoretti sub-location was driven by the fact that it is a cosmopolitan region in Kenya thus representative. Nairobi also has the highest proliferation of television sets and in addition, it hosts Citizen TV's headquarters.

The target population was residents of Dagoretti location including both adults and children who own television sets as well as employees of Citizen TV. The Kenyan population census of 2009 shows that Dagoretti Sub County has an estimate population of 119,020 who own television sets (Kenya National Bureau of Statistics (KNBS, 2014)

Stratified Random sampling was adopted in selecting study participants especially residents of Dagoretti sub location. Stratified random sampling is a method where the population is divided into smaller groups called strata. This method is suitable since the nature of programming usually fragments viewers into target audiences and thus representation of audience fragments will be achieved. In this study, the population was divided into two strata's namely children and adults. In addition a purposive sampling was used to select employees of Citizen TV who participated in this study. Purposive sampling is a sampling technique that allows a researcher to use cases that have the required information with respect to the objectives of his or her study present Mugenda and Mugenda (1999).

The researcher made contacts with the selected respondents with the use of telephone and face-face for the participation of this survey research. The process continued until the researcher had at least 220 respondents willing to participate in this research. A questionnaire was sent out to each respondent with a letter explaining the purpose of this research and to complete a survey. Each selected respondent received a summary of the research result for the participation.

The researcher picked $30 \%$ of the total population which 119,020 and the sample are 35,766 respondents. However due to the nature of the study, the researcher selected 220 members of the public and 20 employee of Royal Media Services to participate in the study.

The study used both interviews and questionnaire to obtain primary data because they are fast, cheap and can be selfadministered (Mugenda \& Mugenda, 2003). The instrument was used since it was considered reliable and capable of obtaining detailed information on the topic of study. The questionnaire contained both open and closed ended questions for the purpose of giving the respondents a chance to provide more detailed information. The questionnaire was used to obtain data from people residing in Dagoretti sub-location 


\section{International Journal of Science and Research (IJSR) \\ ISSN (Online): 2319-7064 \\ Index Copernicus Value (2013): 6.14 | Impact Factor (2015): 6.391}

while interview schedule was used to obtain information from selected employees of Citizen TV who included: program developers, editors and TV producer and some children to get in-depth information on the programmes.

Gay (1992) asserts that reliability is the degree to which a test consistently measures. Mugenda and Mugenda (1999), defines reliability as a measure of the degree to which a research instrument yields results after repeated trial. Before the actual data collection, piloting of 10 questionnaires was done to test if the readers will understand the questions. This will help to find out if the questions asked would be interpreted as the researcher intended them to be.

\section{Data analysis}

The study analyzed both quantitative and qualitative data. Data analysis began with editing, coding and tabulation of data according to research questions. Achola (2007) states that analysis means ordering, categorizing, manipulating and summarizing of data to obtain answers to research questions. The data was analyzed using Statistical Package for Social Sciences (SPSS). Information will be presented using frequency tables, bar graphs, pie charts and graphs.

\section{Response Rate}

A total of 220 questionnaires were constructed, administered to the respondents (members of the public) for the researcher to collect them at a later date. At the end of the study, only 185 questionnaires were returned with 35 not returned or unfilled making the researcher to regard them as spoiled. Returned questionnaires were coded, entered into the computer and analyzed; the overall response rate was $84 \%$.

\section{Distribution of Respondents by Age}

The local TV programs are the most powerful and influential especially among the young people aged between 8-18 years (See table 1). Furthermore the local TV programs are popular among people below 40 years and most all these programs are targeting those groups. Table 3 , shows that local TV programs are not popular among people aged 42 years. This implies that they are likely disinterested on local program or watch TV at a specific time, for example news time and emerging issues.

Table 1: Age bracket

\begin{tabular}{|c|c|c|}
\hline Description & Frequency & Percentage \\
\hline $8-18$ yrs & 68 & $37 \%$ \\
\hline $19-29$ yrs & 30 & $16 \%$ \\
\hline $20-30$ yrs & 55 & $30 \%$ \\
\hline $31-41$ yrs & 20 & $11 \%$ \\
\hline $42>$ yrs & 12 & $6 \%$ \\
\hline Total & 185 & $100 \%$ \\
\hline
\end{tabular}

Authors (2015)

Whether respondents watch local programs on Citizen TV According to McDowell (2006), Media maintains its brand management. In fact $54 \%$ of the respondents interviewed maintained that they prefer Citizen TV's local programs and have been watching. And perhaps considering the competition for viewers there is an attempt by Citizen to tailor its programs to suit the needs of local residents, most certainly to offer them an edge in maintaining its market. In addition the findings reveal that people watch Citizen TV but only news. This implies programs developer's wants consumers perceive their brand and their association.

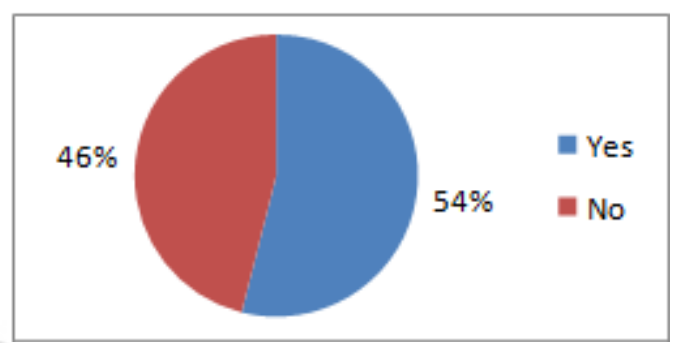

Figure 1: whether respondents watch local programs on Citizen TV

\section{Authors (2015)}

Frequency at which respondents watch Machachari

The frequency of which viewers watch local program varied but generally few recollections of TV programs dealing with their choice. This is without doubt linked with both the variable proportion of local content. As shown in fig.2, Majority 39\% of the study participants indicated they watch every real-time schedule, every repeat $27 \%$ both real time and repeat $20 \%$. Occasionally 8 and those watch local programs on a rare basis constitute $5 \%$.

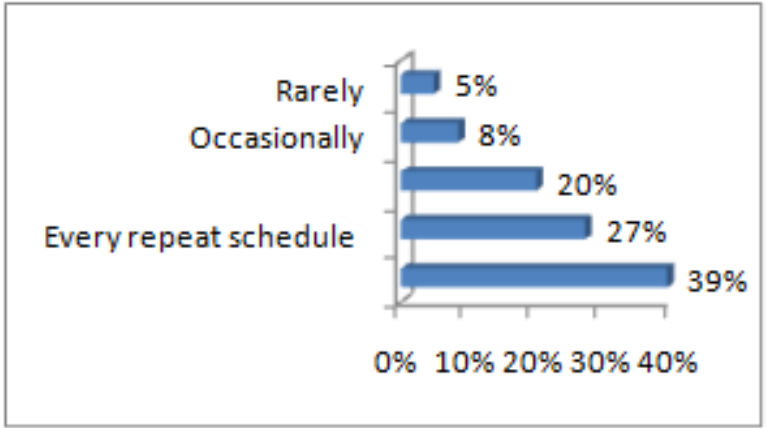

Figure 2: Frequency respondents watch the programs

\section{Authors (2015)}

Overall description of the information consumed from watching local programmes

The findings from this study shows that $58 \%$ of those interviewed described citizen TV local programs as fairly interesting with $33 \%$ who view the programmes as very interesting arguing that Citizen TV local programming makes them own the programs. Furthermore less than $10 \%$ were not very interesting and disinteresting. 


\section{International Journal of Science and Research (IJSR) \\ ISSN (Online): 2319-7064}

Index Copernicus Value (2013): 6.14 | Impact Factor (2015): 6.391

Table 2: Overall descriptions of local programmes in Citizen TV

\section{Authors (2015)}

\begin{tabular}{|c|c|c|}
\hline Description & Frequency & Percentage \\
\hline Very interesting & 55 & $33 \%$ \\
\hline Fairly interesting & 95 & $58 \%$ \\
\hline Not very interesting & 20 & $6 \%$ \\
\hline Disinteresting & 10 & $3 \%$ \\
\hline Total & 185 & $100 \%$ \\
\hline
\end{tabular}

Information I consume influences my strong choice for watching Citizen TV

As shown in fig. 3 this study suits Rusell (2002) description of the concept of products placement a method that is being integrated frequently in the content of mass media programming. By looking into Kenyan consumers, results from this study clearly shows development of local program as Citizen TV preferred brand. Considering the media segmentation in Kenya, majority $40 \%$ of the respondents agreed that the information they consume through watching Citizen TV local programme influenced their strong choice for viewing similarly $27 \%$ indicated strongly agree, $40 \%$ indicated agree, undecided constituted $13 \%$ those disagreed comprised $9 \%$ and lastly $11 \%$ strongly disagreed.

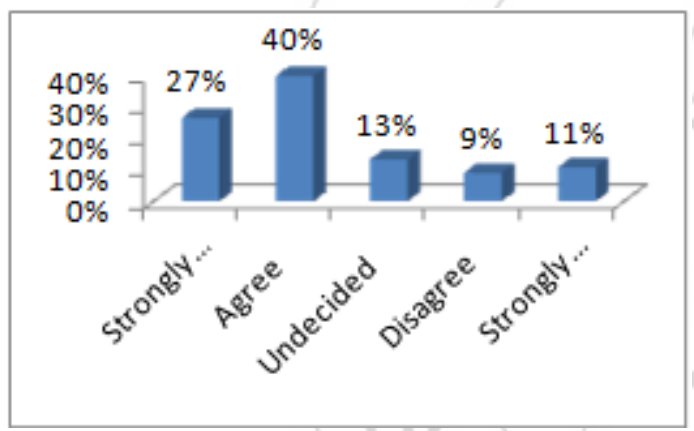

Figure 3: Local programs influences my strong choice for viewing Citizen TV

\section{Authors (2015)}

\section{Influence of TV Characters on the individual's behaviour}

Russell et al (2004) have presented evidence that products placed in a program do affect cognitive measured in relation to Para social relationship but point out the need to study these effects at the effective and donatives level. Consequently this study explores to what extent viewer-character relationship influence awareness associations attitudes and attachment. It is believed that the stronger the relationship between viewers and characters, positive associations and attitudes are more likely to be developed. Moreover the stronger the relationship the more likely is to influence attachment as viewers are believed to have a stronger desire to copy the characters and hence the media tend to maintain or develop more local programs brand identity. In the study, children who watched Machachari confessed to copying the actors morals by being obedient to parents, dedicated to school work and knowing of their responsibility both in school and at home.
Table 3: Influence of TV Characters on the individual's behaviour

\begin{tabular}{|c|c|c|}
\hline Description & Frequency & Percentage \\
\hline Strongly agree & 66 & $34 \%$ \\
\hline Agree & 45 & $27 \%$ \\
\hline Undecided & 35 & $21 \%$ \\
\hline Disagree & 22 & $7 \%$ \\
\hline Strongly disagree & 17 & $10 \%$ \\
\hline Total & 185 & $100 \%$ \\
\hline
\end{tabular}

\section{Authors (2015)}

Perception on How Citizen TV Programmes Shape Social Behaviour in Their Environment

In order to find out how the Citizen TV locally generated programmes shown on the TV stations shape viewers world view concerning social behaviour, Table 9 below shows a distribution of the respondent's responses. It is important to also note that the viewers indicated that in learning how to interact with their peers, other social institutions also play a role.

Table 4: Perception on How Citizen TV Programmes Shape Social Behaviour in Their Environment

\begin{tabular}{|c|c|c|c|}
\hline Responses & $\begin{array}{c}\text { Ilearn how to } \\
\text { interact with my } \\
\text { peers from local } \\
\text { programmes on } \\
\text { TV }\end{array}$ & $\begin{array}{c}\text { I learn } \\
\text { from other } \\
\text { social } \\
\text { institutions }\end{array}$ & $\begin{array}{c}\text { Locally generated } \\
\text { programmes keep } \\
\text { me informed on } \\
\text { happenings in my } \\
\text { enviroment }\end{array}$ \\
\hline Strongly agree & $22.60 \%$ & $19.90 \%$ & $34.40 \%$ \\
\hline Agree & $36.80 \%$ & $40.90 \%$ & $34.70 \%$ \\
\hline Undecided & $24.00 \%$ & $26.70 \%$ & $19.00 \%$ \\
\hline Disagree & $11.60 \%$ & $9.80 \%$ & $9.80 \%$ \\
\hline Strongly disagree & $5.00 \%$ & $2.70 \%$ & $2.10 \%$ \\
\hline Total & $100.00 \%$ & $100.00 \%$ & $100.00 \%$ \\
\hline
\end{tabular}

The Motivational Factors for Watching Locally Generated TV Program among Dagoretti Location Residents

Table 5 below shows the distribution of the different motivational factors for watching Citizen TV Machachari programme. Majority $29 \%$ of respondents especially children affirmed that watching the programme keeps them informed on happenings in their environment and more so made them relate with the character. In addition $22 \%$ of the respondents indicated that they learnt how to interact with their peers from entertainment programmes they watch on TV. The findings further shows that $19 \%$ of the respondents indicated they watch for social interaction, entertainment 13\%, $7 \%$ for arousal (drama) and character progression 9\%.

Table 5: Distribution of motivational factors for watching Machachari

\begin{tabular}{|c|c|c|}
\hline Description & Frequency & Percentage \\
\hline Relate to character & 58 & $29 \%$ \\
\hline Social interaction & 41 & $19 \%$ \\
\hline Entertainment & 22 & $13 \%$ \\
\hline Learning & 37 & $22 \%$ \\
\hline Arousal (drama) & 12 & $7 \%$ \\
\hline Chratacter progression & 15 & $9 \%$ \\
\hline Total & 185 & $100 \%$ \\
\hline
\end{tabular}

Authors (2015)

Volume 5 Issue 5, May 2016 www.ijsr.net 


\section{International Journal of Science and Research (IJSR) \\ ISSN (Online): 2319-7064 \\ Index Copernicus Value (2013): 6.14 | Impact Factor (2015): 6.391}

The answers to the question were further elaborated in the in depth views of the children on how Machachari programme shape their social behaviour were sought. They were asked what social values they learnt from the programmes they watched. John Kariuki said:I have seen many Machachari characters that fight, disrespect their parents and abscond classes in school. In the programme, such characters suffer the repercussions.

The findings of this research is in line with the Social Learning theory that suggests that much learning takes place through observing the behaviour of others, especially through the medium of television. Severin and Tankard (2001) were of the view that many of the effects of the mass media might take place through the process of social learning. These effects according to them might include but not limited to people learning how to wear new fashions, people getting lessons on how interact on dates, and people assimilating behaviours that may be identified with masculinity or feminists.

\section{Summary of Findings}

This study sought to find out the impact of locally generated TV programmes with special focus on Citizen TV Machachari. It attempted at examining whether these local television plays a significant role in the behaviour learnt and exhibited by the viewers in their immediate environment. From available literature reviewed, television has become a part of the daily life of its audience and has transformed the traditional functions of the mass media which is to inform, educate and entertain due to its potential of sight and sound. It was also discovered from available statistics that more than 95 per cent of households in Kenya urban own at least one television set and television plays on an average of about seven hours daily and most of its audience are young people.

The research findings indicate that local broadcast programs especially for Citizen TV are greater in influencing viewer's awareness on their environment. Results showed that respondents were able to recall and recognize local program to a much greater extent, which supports Paivio's (1990) dual coding theory, that brands are more easily recalled and recognized when both the visual and verbal subsystems are activated.

The results of the study showed that Kenyan viewers especially youth and children frequently watched Machachari as their favourite programme. In addition parents also watched these programme because they believe such programme can add value to their children compared to the foreign which can impact the young ones negatively. This programme impacted positively on parents especially on parenthood responsibilities. Parents pointed out that they understood how to handle challenges faced by their school going children. Most learned to respect the views of their children unlike in the past where a child was not supposed to talk their mind to their adults. With this in mind, they have been able to find a balance between their children desires and their aspirations. Parents have also been motivated to pay more attention to their children's academics. Others learned that a stable family life provides a conducive environment for their children to perform well in school since they are able to concentrate in school without the fear of thinking about family squabbles. In general, Machachari impacted the need of responsible parenthood to parents. This establishes the fact that the frequent exposure of viewer's to television plays a significant role in shaping their social behaviour.

Children and adults (excluding parents) also learned and practiced a lot of themes that the local programs conveyed to them. Primary school children have learned that social classes should not create a barrier when it comes to friendship. This they learned when they saw children in Machachari playing with their peers both in slums and rich estates. Children also learnt on the importance of sanitation by keeping the environment clean. This they attribute to an episode where they saw children having running stomachs due to the poor hygiene and a dirty environment around them.

National cohesion and integration has been fostered among children since they watch people in Machachari living together peacefully regardless of their age, ethnic and social backgrounds. One child recalls of an episode where the children were calling for peace in the run up to elections since they did not want violence that will separate them from their friends and neighborhoods. In general, Machachari has been able to instill positive morals to children at a very young age and this has shaped their morals.

\section{Conclusions}

Respondents who were included in the research were 8 years and older, living in Dagoretti location in Nairobi County. To participate in the research, respondents had to have been regular consumers of the specific TV program within the product category, which in this case meant that they had to have consumed the product within a week prior to being interviewed.

From the data gathered and analyzed, it was evident that there was a significant relationship between the exposure to locally generated television programmes and its role in shaping their social behaviour. It was also noted that the influence of the programmes on the viewers could be negative or positive depending on the individual and the nature of TV programmes they are exposed to. Moreover, the respondents admitted that the programmes shown on Citizen Television portray the modern lifestyle, although some of them declined that it was the ideal lifestyle which they will like to emulate. Further based on the findings presented above, it was observed that some respondents agreed that there are some aspects of the lifestyle of characters that they learn from such as celebrities. One respondent, Brian Kimani said "I don't think I have actually seen any but there are some parts that I just pick. There's actually no one that is a complete epitome of how I want to live my life... Most celebrities, their marriages don't usually last that long. You find them getting married like five times in ten years." 


\section{International Journal of Science and Research (IJSR) \\ ISSN (Online): 2319-7064 \\ Index Copernicus Value (2013): 6.14 | Impact Factor (2015): 6.391}

It is also necessary to point out that it was established in this study that there was heavy exposure to locally generated TV by the teenagers, as they admitted that they spent a minimum of much time watching it. This was particularly more for those who prefer Machachari. During the interview some of them stated that they could spend all day watching Citizen TV's Tahidi High and Machachari. Therefore, they learnt some social values from TV such as behaving in school, relating with parents, communication, family life, etc.

\section{Recommendations}

From the study it was observed that locally generated TV programmes (such as Machachari) plays a significant role in shaping the social behaviour of viewers as a result of the nature of TV programmes they are exposed to. However, the influences of these programmes are insidious. They cannot be hindered from consuming these programmes; nevertheless, the following recommendations should be taken into consideration in order to minimize its negative influence on the viewer's social behaviour:

1) This study advocate's for increased locally generated television programming. TV viewers cannot be hindered from watching these programmes, even though not all the programmes have negative contents, but the entertainment TV stations as part of their social responsibility must ensure that entertainment programmes with demoralizing contents are not shown at prime time.

2) Locally generated TV programmes such as Tahidi High and Machachari with high positive social values should be emphasized, while the negative social values should be deemphasized.

3) The family is one social institution that also plays a vital role in shaping the social behaviour of teenagers. Therefore, parents and guardians should devote adequate time to educate their wards who are children on what they watch on the television stations. This is because most times they cannot effectively regulate or monitor what their teenage wards watch.

4) The regulatory bodies should put all hands on deck so as to ensure that broadcasting standards are not compromised. The government through Communication Authority of Kenya has the statutory responsibility of "regulating and controlling the broadcast industry; promoting Kenya indigenous cultures, moral and community life through broadcasting.

\section{References}

[1] Abu-Lughod, L. (1993). Writing Women's Worlds: Bedouin Stories. USA: University of California Press.

[2] Alwael, H., Connolly, D., Barron, L., \& Paull, B. (2010). Development of a rapid and sensitive method for determination of cysteine/cystine ratio in chemically defined media. Journal of Chromatography A, 1217(24), 3863-3870.
[3] Aslama, M. (2009). Playing house: Participants' experiences of Big Brother Finland. International Journal of Cultural Studies, 12 (1), 81-96.

[4] Blumler, J. G. (1985). The social character of media gratifications. In K. E. Rosengren, L. A. Wenner,\& P. Palmgreen (Eds.), Media gratifications research: Current perspectives (pp. 41 59). Beverly Hills, CA: Sage.

[5] Cowell, S. (2003). All together now! Publics and participation in American Idol. Invisible Culture, 1-12.

[6] Dozier, D., \& Rice, R. (1984). Rival theories of electronic newsreading. The new media, 103-128.

[7] Hill, A. (2002). Big Brother The Real Audience. Television \& New Media, 3(3), 323-340.

[8] Holmes, S. (2004). Reality goes Pop! reality TV, popular music, and narratives of stardom in Pop Idol. Television \& New Media, 5(2), 147-172.

[9] Kandie, P. (2001). A study of the strategic responses by Telkom Kenya Limited in a competitive environment. Unpublished MBA project, University of Nairobi.

[10] Karoney, F. (2008). Competitive strategies adopted by the Kenya Television Network (KTN) of the Standard Group (Doctoral dissertation).

[11] Katz, E., \& Lazarsfeld, P. F. (1955). Personal Influence, The part played by people in the flow of mass communications. Transaction Publishers.

[12] Keane, M., Fung, A. Y. H., \& Moran, A. (2007). New television, globalization, and the East Asian cultural imagination. Hong Kong: Hong Kong University Press.

[13] Kiptugen, E. J. (2003). Strategic Responses to a Changing Competitive Environment. A Case Study of KCB. Unpublished MBA project, University of Nairobi.

[14] Lim, J. B. Y. (2008). Reinventing nationalism: The politics of Malaysian Idol on culture and identity in postcolonial Malaysia. In Y. Kim (Ed.), Media consumption and everyday life in Asia (pp. 70-82). New York: Routledge

[15] Lowery, S. (1983). DeFleur.

[16] Mbugua, A. M. (2006). Competitive strategies adopted by mainstream daily print media firms in Kenya. Unpublished MBA project, University of Nairobi.

[17] McClung, S., Pompper, D., \& Kinnally, W. (2007). The functions of radio for teens: Where radio fits among youth media choices. Atlantic Journal of Communication, 15(2), 103-119.

[18] McDowell, W. S. (2005). Selling the niche: a qualitative content analysis of cable network business-to-business advertising, The International Journal on Media Management, 6(3\&4): 217-225.

[19] McQuail, D. (1994). Mass communication and the public interest: Towards social theory for media structure and performance. Communication theory today, 235-53.

[20] McQuail, D. (1994). Mass communication and the public interest: Towards social theory for media structure and performance. Communication theory today, 235-53.

[21] Muganda, R. E. (2007). Competitive Strategies Adopted by Nation Media Group Limited (Doctoral dissertation, University of Nairobi). 


\section{International Journal of Science and Research (IJSR) \\ ISSN (Online): 2319-7064}

Index Copernicus Value (2013): 6.14 | Impact Factor (2015): 6.391

[22] Mugenda, O.M. \& Mugenda A. G. (2003), Research Methods: Quantitative \&Qualitative Approaches. Revised Edition. Nairobi: Acts Press.

[23] Nabi, R. L., Biely, E. N., Morgan, S. J., \& Stitt, C. R. (2003). Reality-based television programming and the psychology of its appeal. Media Psychology, 5(4), 303330.

[24] O'Reilly, R. C., He, Z., Bloedon, E., Papsin, B., Lundy, L., Bolling, L., ... \& Deutsch, E. S. (2008). The role of extraesophageal reflux in otitis media in infants and children. The Laryngoscope, 118(S116), 1-9.

[25] Paivio, A. (1990). Mental Representations: A Dual Coding Approach. New York: Oxford University Press

[26] Raphael, C. (2009). The political economic origins of Reality TV. In S. Murray \& L. Ouellette (Eds.), Reality TV: Remaking television culture (pp. 119-136). New York: New York University Press

[27] Roscoe, J. (2001). Real entertainment: new factual hybrid television. Media International Australia incorporating Culture and Policy, 100(1), 9-20.

[28] Russell, T. A., Schmidt, U., Doherty, L., Young, V., \& Tchanturia, K. (2009). Aspects of social cognition in anorexia nervosa: Affective and cognitive theory of mind. Psychiatry Research, 168(3), 181-185.

[29] von Feilitzen, C., \& Roe, K. (1992). Eavesdropping on adolescence. An exploratory study of music listening among children. Communications, 17(2), 225-244.

[30] Wimmer, R. D., \& Dominick, J. R. (1994). An introduction to mass media research. California: Wadsworth. 